\title{
Toward an Intercultural Rhetoric: Improving Chinese EFL Students' Essay Writing through Outline Writing
}

\author{
Fang Li \\ Xi'an International Studies University, Xi'an, China \\ Yingqin Liu \\ Cameron University, Lawton, USA
}

\begin{abstract}
This study explores the effects of teaching EFL students to use an outline in their English essays. The researchers maintain that using outlines can raise students' awareness of different audience expectations embedded in the rhetoric of the target language (English) and culture and can improve their English academic writing. The study was based on a four-week long case study at a university in Xi'an, China, in which 24 Chinese EFL students at the College of Translation Studies participated. A discourse analysis was conducted by comparing the Chinese EFL students' English essays produced at the beginning of the study with those produced at the end of the study after learning and practicing outlining for writing the English essays. Email inquiries were used for understanding the participants' viewpoints on learning how to write English essay outlines. The findings reveal that teaching EFL students to use outlining in their English essays is an effective way to help them improve their essay writing. Not only can it enhance the students' understanding about using the English thesis statements, but it can also help improve the use of related, logical, and specific detailed examples to support the main ideas in their essays. The email inquiries also revealed that the students believe that outline learning helped them to understand the differences between Chinese and English essay writing. The implications of the study for intercultural rhetoric are also discussed.
\end{abstract}

Index Terms - outline writing, EFL students, intercultural rhetoric, Chinese and Western rhetoric

\section{INTRODUCTION}

Contrastive rhetoric (Kaplan, 1966) originally posits that language and writing are cultural phenomena, that different cultures may have different rhetorical tendencies, and that linguistic patterns and rhetorical conventions of the first language (L1) may cause interference with students' second language (L2) writing (Connor, 1996). As more research in second language writing develops, new interpretations have been added to contrastive rhetoric, leading to a new theory of intercultural rhetoric. This theory advocates that we should contextualize rhetoric culturally and emphasize that writing as communication is influenced by culturally specific rhetorical conventions and that persuasion is affected by audience's culturally defined expectations (Connor \& Traversa, 2014, p.19).

In fact, recent research in intercultural rhetoric-oriented writing instruction has reported promising results for teaching international students. These studies showed improved writing effectiveness when students are taught audience expectations and shown ways to avoid negative transfer from L1 to L2. Xing, Wang, \& Spencer (2008) compared two sets of student writing. The first comparison was between Chinese writing by native Chinese students and English writing by native English speakers and with English writing by the Chinese students in the context of taking an e-course. Then, they compared Chinese writing with English writing accomplished by Chinese students who did not take an ecourse. The results showed that the group using the e-course was successful in learning about defined aspects of English rhetoric in academic writing, ... because the e-course seemed to enhance their understanding of the writing conventions in their L1 and L2 (Xing, Wang, \& Spencer, 2008, p. 71). In addition, Yoshimura's study (2002) showed the effectiveness of using the students' L1 in an EFL writing class in Japan while Walker (2011) recommended using teacher conferencing and peer-response activities to help his Southeast Asian college students engage in more writing to become more familiar with the writing conventions of the target language (English). Thus, all these studies seem to demonstrate the important roles that both L1 and L2 writing conventions could play in improving EFL students' English writing.

Likewise, drawing insight from intercultural rhetoric, the current study explores how EFL writing teachers may use a comparative writing approach to teach EFL students English academic writing. Indeed, this approach aims to make the Chinese EFL students aware of both similarities and differences in the rhetorical organizational patterns of their native language (L1) and English (L2). Specifically, this study used English essay outline instruction to meet this goal.

An outline is a "blueprint" or "plan" for an essay and is a short, organized description of what will be contained in that essay. Taylor (2012) claims, "I believe there are two special advantages to using an outline. First, as you construct 
the organizational scheme for your paper, the use of an outline will quickly reveal where more research is needed. Second, the outline also exposes items that are unnecessary and allows you to jettison them early, before they become unneeded distractions diluting the coherence of your presentation" (p. 205). The authors of the present study also maintain that a well-constructed outline can literally display the "picture" of the development of the whole essay and that using an outline may help the EFL students "see" the connections between their L1 rhetorical patterns and discourse styles with those of the L2 (English) rhetoric. It may also provide a step- by- step learning experience for the EFL students to identify and organize their ideas according to English rhetorical conventions. So, we established two hypotheses for this study:

(1). Teaching English essay outlining can help EFL college students understand English rhetorical/writing convention better and improve their English essay writing.

(2). Teaching English essay outline learning can help EFL college students to understand the different rhetorical preferences in essay writing between Chinese and English rhetoric.

\section{THE THEORETICAL FRAMEWORK}

\section{Intercultural rhetoric}

Studies of cross-cultural writing in ESL, namely contrastive rhetoric, began with Robert Kaplan's (1966) research into differences in organization of essays written in English by international students with a variety of backgrounds. Connor \& Traversa (2014) stated that the two cornerstones of contrastive rhetoric are the transfer of first language patterns to a second language, as well as the notion that patterns of language and writing are culture-specific. However, contrastive rhetoric was criticized by researchers and educators in L2 language writing for its reductive view of the L1 influences on L2 discourse and for its methodological problems created by small size samples. To respond to the criticism, scholars such as Connor and Traversa (2014) introduced some concepts from theories of rhetoric and redefined meanings of culture for contrastive rhetoric, renaming the endeavor "intercultural rhetoric." Connor (2008) proposed a multilayered model of intercultural rhetoric. This model includes "three major tenets of intercultural rhetoric: (1) texts need to be seen in their contexts with meaningful contextual and purposeful descriptions, (2) culture needs to be complexified to include disciplinary cultures in addition to national/ethnic cultures, and (3) dynamic, interactive patterns of communication are important to consider, which leads to convergences among cultural differences" (as cited in Connor \& Traversa, 2014, p. 20). Thus, the redefined contrastive or intercultural rhetoric emphasizes the roles of rhetorical purposes for different genres and audience's expectations within a specific cultural writing convention.

Drawing insights from intercultural rhetoric, Casanave (2004) claims that some of the differences that impact writing across cultures include rhetorical patterns of organization, composing conventions, cohesion and coherence patterns, and audience expectations. Further, he recommends that L2 teachers use three approaches in their classrooms to improve EFL students' English writing. These include encouraging their students to carefully analyze the purposes of and audience for their writing to avoid stereotypes of their L1 and L2, asking students to compare paragraph and essay organization between L1 and L2 texts, and engaging students in examining audience expectations in different cultures (Casanave, 2004). To illustrate, he further explained that, for "good writing" in narrative essays, U.S.-based teachers valued logic and strong openings due to English rhetoric, whereas the Chinese teachers valued sentiments and moral messages because of Chinese rhetorical tradition ( $\mathrm{Li}, 1996)$.

2. Chinese rhetoric vs Western/English rhetoric

Since the introduction of Contrastive rhetoric by Kaplan (1966), there has been constant and often heated discussion of Chinese rhetoric vs Western rhetoric. The researchers here will focus on the views that suggest Chinese rhetoric prefers inductive and indirect organization which often results in native English-speaking teachers' confusion with EFL and ESL students' English essays. This is because English rhetoric takes a more straightforward and deductive approach (Fox, 1994). The representative scholars in this view were Kaplan (1996) and Matelene (1985). They held the view that Chinese writing is indirect because they observed that Chinese ESL students used indirect or circular organization in their English writing. Kaplan (1966) argued that Chinese as well as "Oriental” writing in general is indirect (p. 9). He explained that "The paragraph development may be said to be turning and turning in a widening gyre. The circles or gyres turn around the subject and show it from a variety of tangential views, but the subject is never looked at directly" (Kaplan, 1966, p. 10). Matalene (1985) supported Kaplan's assumption and stated that Chinese students did not argue from premises to conclusion, but instead presented assertions in an accumulative fashion. Matalene (1985) then claimed that "to be indirect and to expect the audience to infer meaning rather than to have it spelled out was a defining characteristic of Chinese rhetoric" (p. 801).

In contrast, the Western rhetorical tradition that is based on Aristotelian classical rhetoric favors using a deductive approach over an inductive one. Vries (2000) describes the typical structure of an English language academic essay as: "The expected thought sequence is linear in its development. In written communication in English, for example, the paragraph begins with a topic statement and then proceeds to develop that statement by example and illustrations. The central idea is related to all other ideas in the whole essay, and therefore, a good piece of writing is considered to be unified with no superfluous information" (p. 3). Fox (1994) also states that the expectation of a typical Western academic audience of United States is that, in addition to its structure of a clear and direct thesis statement followed by 
convincing reasons that support it, the argument should be assertive, confident, logical, and "to the point" without irrelevant digressions.

Drawing the insights from the above theories, we concur with the perspective that we should contextualize rhetoric culturally and emphasize that writing as communication is influenced by culturally specific rhetorical conventions (Connor \& Traversa, 2014, p.19). Xing et. al (2008) point out that, since L2 writers bring with them various cultural experiences that can influence their writing, EFL teachers need to teach students to be aware of L1 and L2 writing conventions that focus on essay structure and readers' expectations. Thus, EFL students can learn not only the forms of language but also the cultural constraints associated with the forms and the effects of choosing a particular form. Understanding those contrastive aspects of two types of cultural rhetoric constitutes an important step for ESL and EFL students to attain awareness on some L2 essay distractions related to their L1 writing convention and culture. We maintain that teaching EFL students L2 outline writing is a useful way to help students understand the similarity and differences between their L1 and L2 writing conventions. This should lead to greater success in their English academic writing.

\section{METHOD}

\section{Participants and setting}

This paper presents a case study of research that lasted 4 weeks at one university in Xi'an, China during the spring semester of 2017. Twenty-four EFL sophomores (four male students and twenty female students) who were enrolled in the required English Writing course participated in the study. The English Writing class met twice a week and lasted for 45 minutes for each class period. The participants all majored in Translation Studies at the university.

2. Procedures

Stage 1: During the spring semester in 2017, the student participants were given an after-class essay assignment by their writing instructor (one of the researchers) on the topic of the use of smartphones. Here is the writing prompt (the researchers created):

Instruction: Smartphone use has been very popular in our society. What will happen to people's lives if, one day, they have to live without the smartphones? Please fully respond to this question in a complete formal English essay. You have two weeks' time to finish this after-class English essay.

Stage 2: At the end of the given two weeks' time, the instructor collected the essays. Then, the instructor provided the participants with a series of English essay outline teaching activities, which were carried out in two 45- minutewriting classes in the third week. The teaching contents included the following topics in a chronological order:

A. Teaching and practicing the key concepts of English essay writing

a. Providing a PowerPoint lecture on English essay structure

b. Providing a PowerPoint lecture on topic sentences in English paragraphs

c. Providing a PowerPoint lecture on thesis statements in English essays

d. Providing the students with exercises on writing thesis statements and on English essay structure.

B. Teaching an English essay outline

a. Lecturing about what an outline is

b. Lecturing about why an outline should be used

c. Explaining the relationship between an essay outline and an essay structure

d. Providing the students with exercises on using outline on a sample English essay

e. Explaining how to create the two types of outlines

- Creating a topic outline

- Creating a sentence outline

Stage 3: When the two class periods from Stage 2 were completed, the instructor reassigned the same essay topic as the first one to the student participants but required them to create an outline this time before they started to write this version. Additionally, the students were given one week's time to finish this second essay. During this fourth week of the study, none of the student participants had the first essay available to them because the first essays were all handwritten and turned in to the instructor before they wrote the second essays. At the end of the fourth week, the student participants submitted their typed essay outlines and essays. Meanwhile, the instructor also recruited five volunteers from the participants for a follow-up email inquiry about the student participants' reflections on the outline learning.

3. Data collection and instruments

Two types of research data were collected and analyzed by the researchers.

A. The English essays, themselves: the 24 essays written before the students' learned how to use essay outline in their English essays and the 24 essays written after they learned about outlines for their English essays. These two kinds of essays were compared and the emerging themes were described and analyzed.

B. Feedback from the email inquiries: Selected participants discussed their viewpoints on the outline instruction, which was analyzed for the emerging themes.

\section{FINDINGS AND DISCUSSION}


This section presents the findings of and a discussion of the study in response to the two hypotheses introduced earlier and will discuss the significance of the findings.

Hypothesis: (1). Teaching English essay outlining can help EFL college students understand English rhetorical/writing convention better and improve their English essay writing.

The findings from the discourse analysis comparing the participants' essays written before and after learning English essay outlining provide a positive answer to the first hypothesis. The findings reveal two remarkable improvements in the participants' English essays, in the areas of establishing a thesis statement and using detailed specific supporting evidence.

First, the findings from the comparison show that learning to use outlines for their English essays helped the participants better understand the meanings of their thesis statements. According to Lunsford (2016),

Academic and professional writing in the United States contains an explicit thesis statement. The thesis functions as a promise to readers, letting them know what the writer will discuss. Your readers may expect you to craft the thesis as a single sentence near the beginning of the text... A thesis should have two parts: a topic, which indicates the subject matter the writing is about, and a comment, which makes an important point about the topic. (p. 40-41)

The findings reveal that, after learning English outlines, more participants not only established the thesis statements in their essays but also placed them in the right location: the end of the introduction.

TABLE 1 shows the number of essays that included the proper thesis statement in the introduction increased from 5 to 18 after the outline learning.

TABLE 1

(WRITING A THESIS STATEMENT)

\begin{tabular}{|c|c|c|}
\hline Improvement 1 & $\begin{array}{l}\text { Before Learning English Essay } \\
\text { Outlining }(\mathrm{N}=24)\end{array}$ & $\begin{array}{l}\text { After Learning English Essay Outlining } \\
(\mathrm{N}=24)\end{array}$ \\
\hline $\begin{array}{l}\text { Including a } \\
\text { Thesis } \\
\text { Statement at the } \\
\text { End of the } \\
\text { Introduction }\end{array}$ & 6 & 18 \\
\hline $\begin{array}{l}\text { Sample } 1 \\
\text { Introduction }\end{array}$ & $\begin{array}{l}\text { "With technology development, } \\
\text { smart phone became an } \\
\text { incredibly important part in every } \\
\text { people's life. People are saw } \\
\text { playing smart phone everywhere } \\
\text { around subway, restaurant, } \\
\text { classroom and so on" (Student 2). }\end{array}$ & $\begin{array}{l}\text { "Smartphone gets more and more popular and indispensable in everyone's daily life. } \\
\text { You can go out without money, credit cards or maps while without smartphone, you } \\
\text { would not be willing to go anywhere. Moreover, smartphone undertakes most of } \\
\text { your social networking functions. Every time you use WeChat or Facebook to } \\
\text { connect with your friends you use smartphone. Since smartphone takes such an } \\
\text { important role in our life, we may wonder how it would be without smartphone" } \\
\text { (student 2). }\end{array}$ \\
\hline $\begin{array}{l}\text { Sample } 2 \\
\text { Introduction }\end{array}$ & $\begin{array}{l}\text { "Can you imagine a world where } \\
\text { there has not smart phone? How } \\
\text { do people live a life? What the } \\
\text { life will be" (Student 17) }\end{array}$ & $\begin{array}{l}\text { "We're living an era where capturing moments and sharing them using our } \\
\text { smartphones is more important than actually living these moments with whoever is } \\
\text { beside us. Smartphone is such a necessary part of our daily life. Have you wondered } \\
\text { how life would be without a smartphone? In fact, many people cannot imagine a life } \\
\text { without smartphones, and they couldn't live without smartphones. The importance } \\
\text { of smartphones in today's world cannot be overemphasized, from carrying out real } \\
\text { time businesses to fun activities to security checks, not to mention thousands of } \\
\text { phone applications being developed on daily bases to cater for almost all our needs } \\
\text { in all walks of our life. However, personally speaking, we can live a better life } \\
\text { without smartphones. Let us talk about the good of the life without smartphones } \\
\text { from two aspects" (Student 17). }\end{array}$ \\
\hline
\end{tabular}

The two samples before learning the outline here reveal that none of the early introductions include a thesis statement. The introduction (before learning outlines) of sample 1 simply gives some background information on the topic of smartphones while that of the sample 2 only asks some rhetoric questions to get the reader's attention to the topic. However, after learning about outlines, both samples established the thesis statement at the end of the introduction. In sample 1, although the thesis statement, "Since smartphone takes such an important role in our life, we may wonder how it would be without smartphone," still needs to be polished, it at least shows the direction of the essay's development in the coming discussion. That is to say, the thesis statement indicates that the essay will discuss the positive impact of the smartphone on people's lives. In the case of sample 2, the thesis statement, "However, personally speaking, we can live a better life without smartphones. Let us talk about the good of the life without smartphones from two aspects," clearly shows that the essay's main idea will deal with the benefits of not having smartphones in people's lives.

This increase in using English thesis statements in the participants' essays demonstrates that making outlines has helped make the EFL students think about the main point they plan to discuss at the beginning of an essay. Thus, the established main idea would point them in the right direction of the sequential development of the essays. That is to say, it would direct them to further find out the reasons why they think so or believe that idea. This approach of organizing the essay actually reflects what Vries (2000) describes as the typical structure of an English language academic essay. The expected thought sequence is linear in its development, and the central idea is related to all other ideas in the whole essay. So, based on the findings here, we think that it is safe to state that outline writing can help Chinese EFL students understand English writing conventions better (such as establishing a thesis statement in the introduction). 
The second finding that can support the first hypothesis involves the increased use of specific evidence to support their thesis statements. In English, it is well-known that a clear essay structure has three basic parts: introduction, body (discussion) and conclusion. But an effective English essay contains more than just a clear structure. As Lunsford (2016) points out, writers need "to make sure that each paragraph relates to or supports the thesis and that each paragraph has sufficient detail to support the point it is making" (p.77). The findings actually reveal that, after learning to use outline, the number of essays including the related detailed specific evidence to support the thesis statements has risen from 10 to 18 among a total of 24 essays. The following comparative analysis on two participant student essay samples written before and after the outline learning demonstrates this second finding.

We will first examine the Student Sample Essay 1 displayed in TABLE 2.

TABLE 2

(STUDENT SAMPLE ESSAY 1 BEFORE \& AFTER)

\begin{tabular}{|c|}
\hline Before Outline Learning (Student Sample Essay 1) \\
\hline $\begin{array}{l}\text { Life without Cellphone } \\
\text { "With technology development, smart phone became an incredibly important part in every people's life. People are saw playing smart } \\
\text { phone everywhere around subway, restaurant, classroom and so on. } \\
\text { However, if we take their smart phone away all of a sudden, what would happen? Perhaps, at the first moment, they would feel boring } \\
\text { and have no [idea] what to do now or next. Then they would become anxious like ants in a hot pot and start to walk around trying to find } \\
\text { something interesting but without smart phone, nothing is good enough to attract them. At last, they would go mad in the extremely vacuous } \\
\text { world. Because without smart phone, their life became boring and anxious and people can't get away with that. } \\
\text { All in all, without smart phone, human beings would become incredibly horrible" (Student 2). }\end{array}$ \\
\hline After Outline Learning (Student Sample Essay 1) \\
\hline $\begin{array}{l}\text { Outline } \\
\text { 1. Introduction } \\
\text { Smartphone gets more and more popular and indispensable. } \\
\text { 2. Life would become less convenient without smartphone } \\
\text { a) Smartphone increased the efficiency of social functioning } \\
\text { i. Amazon and Taobao } \\
\text { ii. Cashless economy } \\
\text { b) Life would become less convenient without smartphone } \\
\text { 3. Life would be less interesting without smartphone } \\
\text { a) Smartphone changed the way people connecting each other } \\
\text { i) Facebook and WeChat } \\
\text { b) Smartphone brings more fun to daily life. } \\
\text { i) Games and entertainment apps } \\
\text { 4. Conclusion } \\
\text { Life would become very inconvenient and tedious without smartphone. }\end{array}$ \\
\hline $\begin{array}{l}\text { Life without Smartphone } \\
\text { "Smartphone gets more and more popular and indispensable in everyone's daily life. You can go out without money, credit cards or } \\
\text { maps while without smartphone, you would not be willing to go anywhere. Moreover, smartphone undertakes most of your social networking } \\
\text { functions. Every time you use WeChat or Facebook to connect with your friends you use smartphone. Since smartphone takes such an } \\
\text { important role in our life, we may wonder how it would be without smartphone. } \\
\text { Above all, life would become less convenient without smartphone. Smartphone increased the efficiency of social functioning. From } \\
\text { Amazon to Taobao, we use them buying fancy shoes or delicious foods by our smartphone and we can do it on bus or waiting in line. When } \\
\text { we have no money, but need to pay for something, now we can do it with our smartphone, which is called cashless economy. All of those } \\
\text { brought convenience to every aspect of our daily life, without smartphone, it would become less convenient. Also, life would be less } \\
\text { interesting without smartphone. Smartphone changed the way people connecting each other. With smartphone apps as Facebook and WeChat, } \\
\text { we make new friends or chat with old fellows no matter how far away we really are. What's more, smartphone brings more fun to daily life. } \\
\text { We play games on it from day to night, twitter, YouTube and so on. However, without smartphone, all [the fun] would be lost. } \\
\text { Life would become very inconvenient and tedious without smartphone." ( Student 2) }\end{array}$ \\
\hline
\end{tabular}

In the following TABLE 2-a, we exhibit our comparative discourse analysis on the essay improvements for the Student Sample Essay 1 before and after outline learning.

TABLE 2-A

(AN ANALYSIS ON THE STUDENT SAMPLE ESSAY 1 BEFORE \&AFTER)

\begin{tabular}{|l|l|l|}
\hline Essay Structure and Support & $\begin{array}{l}\text { Analysis on before Outline Learning } \\
\text { (Student Sample Essay 1) }\end{array}$ & Analysis on after Outline Learning (Student Sample Essay 1) \\
\hline Introduction & $\begin{array}{l}\text { The introduction is too brief in } \\
\text { introducing the topic and doesn't have a } \\
\text { thesis statement. }\end{array}$ & $\begin{array}{l}\text { The introduction has adequate background information on the } \\
\text { topic and contains a thesis statement at the end of the } \\
\text { introduction. }\end{array}$ \\
\hline $\begin{array}{l}\text { Body paragraphs with } \\
\text { specific evidence }\end{array}$ & $\begin{array}{l}\text { The discussion presents some random } \\
\text { general ideas on the negative effects of } \\
\text { without smartphones in people's lives. It } \\
\text { does not provide any specific examples } \\
\text { to explain these general ideas. }\end{array}$ & $\begin{array}{l}\text { The discussion to explain and support the thesis statement is } \\
\text { coherently and specifically organized due to the use of related } \\
\text { topic sentences with specific related details and examples. For } \\
\text { instance, the meaning of the topic sentence, "life would become } \\
\text { less convenient without smartphone," becomes very clear when } \\
\text { the use of the related specific details such as "Amazon and } \\
\text { Taobao and cashless economy..." are introduced and explained. }\end{array}$ \\
\hline Conclusion & $\begin{array}{l}\text { The conclusion is short and confusing } \\
\text { due to the wrong diction, " horrible." }\end{array}$ & $\begin{array}{l}\text { The conclusion is short but restates the thesis statement and can } \\
\text { be further expanded. }\end{array}$ \\
\hline
\end{tabular}


Next, we will look at the Student Sample Essay 2 displayed in TABLE 3.

TABLE 3

(STUDENT SAMPLE ESSAY 2 BEFORE \& AFTER)

\section{Before Outline Learning (Student Sample Essay 2)}

"Can you imagine a world where there has not smart phone? How do people live a life? What the life will be.

People will live a happier life. They are not bound by their smart phone and surf the internet all the time, influenced by all kinds of [information]. They will spend more time communicating with their family, friends and strangers. They will not stay alone with their smart phone. By contrast, they will stay with books and participate in a variety of activities. They can do whatever they like.

Of course, the life will be less convenient. Smart phones can assist us in many daily affairs. It also can make our life more effective, connecting us with the world. We can know what happened in other countries instantly

Let's risk off with our life without smart phone." (Student 17)

After Outline Learning (Student Sample Essay 2)

Outline

Life Without Smartphone

Life Without Smartphones ---- The Good

\section{Introduction}

Have you wondered how life would be without a smartphone? In fact, many people cannot imagine a life without smartphones, and they couldn't live without smartphones. The importance of smartphones in today's world cannot be overemphasized, from carrying out real time businesses to fun activities to security checks, not to mention thousands of phone applications being developed on daily bases to cater for almost all our needs in all walks of our life. However, personally speaking, we can live a better life without smartphones. Let us talk about the good of the life without smartphones from two aspects.

II. Body

A. The life without smartphones benefits our family.

1. Set a good example for our kids

a) Be devoted to reading

b) Listen to their story and play with them

2. Spend more time with our family

a) Take part in family's activities

b) Communicating with our family members

B. The life without smartphones makes our work better.

1. Promote our efficiency

a) Not be distracted

b) Be mindful

2. Devoting more time to our work

a) Not be addicted social media

b) Communicating with colleagues

III. Conclusion

People who quite living their lives on their smartphones and begin to live them in real time and space will experience and enjoy the better life.

Life Without Smartphone

We're living an era where capturing moments and sharing them using our smartphones is more important than actually living these moments with whoever is beside us. Smartphone is such a necessary part of our daily life. Have you wondered how life would be without a smartphone? In fact, many people cannot imagine a life without smartphones, and they couldn't live without smartphones. The importance of smartphones in today's world cannot be overemphasized, from carrying out real time businesses to fun activities to security checks, not to mention thousands of phone applications being developed on daily bases to cater for almost all our needs in all walks of our life. However, personally speaking, we can live a better life without smartphones. Let us talk about the good of the life without smartphones from two aspects.

The life without smartphones benefits our family. We must be familiar with the situation where the family members are sitting together and they nearly don't talk to each other, just burying themselves in their smartphones. The communication is becoming less and less. What's the worse is that more and more children are also addicted to the smartphone and using their parents' smartphones to play games in their spare time. Contrary to the situation, people will spend more time with family members. Parents can read books with their children and help them form a good habit. Children learn to read in their spare time and would like to share their stories with parents. These things are good for the development of children. Communicate with our family members rather than spend time with smartphones will make the relationship stronger. Furthermore, we can have time to organize all sorts of activities for our family. We are getting together to enjoy the joys and the moments. Family's life will be full of happiness.

The life without smartphones makes our work better. We've felt such peace in our every day. We don't feel rushed or too distracted. We are paying attention to whatever we are doing at work. We can hear the birds and notice the plants. We are nicer to ourselves as I'm not wasting time scrolling down on social media. We might think it is weird. It's weird because we live such a rushed life for so long that we forget to feel what it feels not to be in a rush or distracted. Not having a smartphone taught us that we are already there and we aren't distracted by external and internal noise. The mindfulness makes us devoted to our work, promoting our efficiency greatly. We spend more time with our colleagues and communicate the work with them, believing that we all complement each other, and thus help each other learn and grow. If we are addicted to the social media, we would be more pressured and cannot enjoy our work and balance the work and life.

Life without smartphones has helped with achieving some peace and being present. It not only promotes ourselves but also benefits our family and work. People who quite living their lives on their smartphones and begin to live them in real time and space will experience and enjoy the better life.

In the following TABLE 3-a, we present our comparative discourse analysis on the essay improvements for the Student Sample Essay 2 before and after outline learning. 
TABLE 3-A

(AN ANALYSIS ON THE STUDENT SAMPLE ESSAY 2 BEFORE \& AFTER)

\begin{tabular}{|l|l|l|}
\hline Essay Structure and Support & $\begin{array}{l}\text { Analysis on before Outline Learning } \\
\text { (Student Sample Essay 2) }\end{array}$ & Analysis on after Outline Learning (Student Sample Essay 2) \\
\hline Introduction & $\begin{array}{l}\text { The introduction only asks the short } \\
\text { rhetorical questions on the topic, and } \\
\text { it doesn't have a thesis statement. }\end{array}$ & $\begin{array}{l}\text { The introduction has adequate background information on the } \\
\text { topic focusing on the benefits. It established a clear thesis } \\
\text { statement at the end of introduction. }\end{array}$ \\
\hline $\begin{array}{l}\text { Body paragraphs with } \\
\text { specific evidence }\end{array}$ & $\begin{array}{l}\text { The discussion basically answers the } \\
\text { questions raised in the introduction. It } \\
\text { lists both positive and negative effects } \\
\text { of without smartphone in life. But it } \\
\text { does not provide any specific } \\
\text { examples or details to explain these } \\
\text { general ideas. }\end{array}$ & $\begin{array}{l}\text { The discussion is logically organized and the thesis statement is } \\
\text { slearly supported from two focused specific benefits of without } \\
\text { "The life without smartphones benefits our family," and "The life } \\
\text { without smartphones makes our work better." The specific related } \\
\text { details such as spending time with kids through reading books, } \\
\text { talking with family instead of looking at smartphones, less } \\
\text { distraction in work, and not addicted to social media all help to } \\
\text { make the discussion convincing and interesting. }\end{array}$ \\
\hline Conclusion & $\begin{array}{l}\text { The conclusion is short and a bit } \\
\text { contradict to the discussion. }\end{array}$ & $\begin{array}{l}\text { The conclusion summarizes the whole discussion: the benefits of } \\
\text { living without smartphones. It also gives some final thoughts on } \\
\text { the topic. }\end{array}$ \\
\hline
\end{tabular}

We ascribe the above observable improvement (i.e., the participants' using more specific details and examples to support their thesis statements) to the use of outlines in the essays. We can see that the outlines in the students' essays have functioned in three ways, as Lunsford (2016) suggests, “... it can help you see exactly how the parts of your writing will fit together- how your ideas relate, where you need examples, and what the overall structure of your work will be" (p.48). The participants themselves also noted these advantages of outlines. In the email inquiry, when responding to the question on the functions of using an outline in their English essays, one participant wrote, “...It can help me know what I am going to write about. Sometimes even if I have decided which topic should I choose to write about, I am still quite confused about the arguments or detained information that I should write about in my essay. With the help of English essay outlining learning, I have learned how to draw a mind map before writing, which can help me know how to write each paragraph clearly and also speed up my writing" (Participant 12, personal communication, June12, 2017). Another student observed that “... it can help me to organize my thinking and make my writing more logical and contain a clear structure. It also helps me to avoid the influence of my Chinese essay writing, which often gives too much far- attached information and turns around in repeating some similar ideas" (Participant 5, personal communication, June12, 2017). The responses here demonstrate that the EFL participants have become more aware of the possible differences between their English essay writing and their Chinese essay writing. Finally, another participant stated that "... I believe that outline is like a thinking road -map for me, for it makes me avoid distractive information but choose logical details in a clear order. So, using outline can make my essay more complete, logical and clearer in meaning" (Participant 20, personal communication, June12, 2017). Thus, we can state that the findings show that through learning and using English outlines, the EFL students not only can graphically layout the structure of an essay but also can work through prewriting process for choosing related detailed specific support to the thesis.

Now, we will present and discuss the findings for the second hypothesis.

Hypothesis (2): Teaching English essay outline learning can help EFL college students to understand the different rhetorical preferences in essay writing between Chinese and English rhetoric.

The findings from the email inquiry data have provided some interesting and positive answers to this second hypothesis. Specifically, the students' answers from the email inquiry question 2 (see Appendix 1) reveal that the students all were aware of that there existed some different writing approaches between the English and Chinese essay writing and using an outline helped keep them in track with their English essays. Among the five email inquiry responses, four participants pointed out that in their first essays before learning English outline, they actually wrote based on the ways they wrote their Chinese essays. For example, one participant stated,

Yes, in many situations, my English writing is affected by my Chinese writing. In writing Chinese expository essay, we are taught to use examples and background information to persuade the readers for our main idea first and then introduced the main idea at the end of essay, so I followed this approach in my first essay. However, using outline helped me notice that English essay introduces the main idea more directly at the beginning like what we call 'Open the door and see the mountain'. (Participant 9, personal communication, June12, 2017)

Another participant further described her perception on Chinese and English essay writing as follows,

Writing a Chinese essay is very [different] from writing an English essay. The English essay usually [is] based on the structure of "introduction-body-conclusion," but Chinese essay structure [is] more characterized as "beginningfollowing-turning-concluding."

Due to cultural differences, it is difficult for me to get rid of the influence of my mother tongue, thinking in the actual writing process before learning the outline writing. I also use gorgeous language, with celebrity quotes and various rhetorical means. Actually, when we [write] an English essay, we should [be] more direct to express our opinions, [and] the most important thing is [that] any argument needs specific supports. (Participant 12, personal communication, June12, 2017) 
This participant made a very good point when describing about the differences in what people would consider as effective supporting evidence between Chinese and English writing. Still, one participant showed his perception in terms of differences between Chinese and English writing, as the participant stated,

Definitely, I was influenced greatly by Chinese [ways of writing]... I have no need to consider the logic between sentences and paragraphs when writing Chinese because it is a parataxis language that the meaning can be easily known from words, so seldom attention is allocated to logic. By contrast, rigorous logic is significant in English essay just as mentioned before. The different thinking ways cause barriers in writing English, I have to admit. (Participant 5, personal communication, June12, 2017)

To sum up, the findings from the email inquiry support the second hypothesis, and they also agree with Xing et. al (2008)'s research result that L2 writers bring with them various cultural experiences that can influence their L2 writing, but teaching them to compare L1 and L2 writing conventions focusing on essay structure and readers' expectations can help EFL students understand L2 (English) writing convention better. In our study, using English outline for the participant students' L2 English essay writing seems to be productive in helping them do better in their English essays and to make them more aware of the different preferences in Chinese and English writing conventions.

\section{CONCLUSION AND IMPLICATION}

The current study shows that using English outlines can help provide a step- by- step writing experience for the EFL students to identify and organize their ideas according to English rhetorical conventions because a well-constructed outline can literally display the "picture" of the linear or hierarchical development of the whole essay. The study also demonstrates that using outline can help the EFL students "see" the connections between their L1 rhetorical patterns and discourse styles with those of the L2 (English) rhetoric. Thus, using English outlines can help enhance the EFL students' awareness of audience's different expectations in a culturally defined rhetorical situation. Hyland (2003) argues that ESL/ EFL writing instructors in an intercultural communication context need to be aware that cultural factors need to be understood as a potential source of explanation for writing differences and used to recognize that there are numerous ways of "making meanings." In concurring with this assumption, from a perspective of intercultural rhetoric, we also maintain that the outline learning can provide a useful means for both the EFL instructors and students to build a bridge between the L1 and L2 writing conventions through constructing a logical mind map for EFL student writers. Thus, outlining learning would help scaffold the EFL students to understand L2 (English) writing convention better and improve their English essay writing.

\section{APPENDIX. QUESTIONS FOR EMAIL INQUIRIES}

1. How did you like the English essay outlining learning and writing practice? In what ways, did you feel it was helpful for your English essay writing?

2. Do you think your first essay before learning the outline writing was influenced by the ways you write Chinese essays? Or do you think the ways you write a Chinese essay are the same as these of writing an English essay? Why or why not?

3. What were things you liked most about the English essay outlining? What were the things you disliked about this learning experience?

4. What would be the suggestions you like to give for the possible future outline learning and writing in your English essay class?

\section{REFERENCES}

[1] Casanave, C. (2004). Controversies in second language writing: Dilemmas and decisions in research and instruction. Ann Arbor, MI: University of Michigan Press.

[2] Connor, U. (1996). Contrastive rhetoric: Cross-cultural aspects of second language writing. New York, NY: Cambridge University Press.

[3] Connor, U., Nagelhout, E., \& Rozycki, W. V. (eds.) (2008). Contrastive rhetoric: Reaching to intercultural rhetoric. Amsterdam: John Benjamins.

[4] Connor, U. \& Traversa, A. (2014). "The role of intercultural rhetoric in ESP education." CELC Symposium on Culture. http://www.nus.edu.sg/celc/research/books/4th\%20Symposium\%20proceedings/3).\%20Connor\%20and\%20Traversa.pdf (accessed 6/25/2018).

[5] Fox, H. (1994). Listening to the world: Cultural issues in academic writing. Urbana, IL: NCTE.

[6] Hyland, K. (2003). Second language writing. Cambridge, UK: Cambridge University Press.

[7] Kaplan, R. B. (1966) "Cultural thought patterns in intercultural education." Language Learning, 16, 1-20.

[8] Li, X. (1996). "Good writing" in cross-cultural context. Albany, NY: State University of New York Press.

[9] Lunsford, A. (2016). The everyday writer. $6^{\text {th }}$ edition. Boston, MA: Bedford/ St. Martin's.

[10] Matalene, C. (1985). "Contrastive rhetoric: An American writing teacher in China." College English, 47(8), 789-808.

[11] Taylor, R. B. (2012). "The joy of outlining in medical writing." Medical Writing, 23 (3), 205-207.

[12] Vries, K. D. (2002). "Writing 'clearly': Differing perceptions of clarity in Chinese and American texts." Proceedings of the International Symposium on Contrastive and Translation Studies Between Chinese and English, Shanghai, PRC. 
[13] Walker, D. (2011). How to teach contrastive (intercultural) rhetoric: Some ideas for pedagogical application. New Horizons in Education, 59(3), 79-86.

[14] Xing, M., Wang, J., \& Spencer, K. (2008). Raising students' awareness of cross-cultural contrastive rhetoric in English writing via an e-learning course. Language Learning \& Technology, 12 (2), 71-93.

[15] Yoshimura, T. (2002). Formal instruction of rhetorical patterns and the effectiveness of using the L1 in argumentative writing in an EFL setting. (Unpublished doctoral dissertation). Temple University, Japan.

Fang $\mathbf{L i}$ is a lecturer at School of Translation Studies at Xi'an International Studies University, China. He obtained a Ph.D. degree in Instructional Leadership from the University of Alabama, USA, with a concentration in instructional technology in 2016 . He also received his MEd in Literacy/TESL in 2008 from University of Cincinnati, USA. His current research interests and primary practice include: computer-assisted translation, localization, teaching translation and interpretation with VR (virtual reality) and AR (augmented reality), multimedia courseware development, and mobile learning.

Yingqin Liu is an Associate Professor in the Department of English and Foreign Languages at Cameron University, Lawton, Oklahoma, USA. She was granted a doctoral degree in Technical Communication and Rhetoric from Texas Tech University in 2007. She obtained her MA in English, with a concentration in TESL from Western Kentucky University in 2002. Her major research interests are in the theories and practice of intercultural communication and intercultural rhetoric, second language teaching and writing, and technical/ business communication. She has published articles in these areas. 